\title{
Effect of Face Contact Ratio on Load Sharing Based Fillet Stress in Asymmetric Helical Gear Drives
}

\author{
R.Prabhu Sekar*, G.Muthuveerappan \\ Department of Mechanical Engineering, Machine Design Section, Indian Institute of Technology, Madras, Tamil Nadu \\ *Corresponding Author: prabhusekar.r@gmail.com
}

Copyright (C) 2014 Horizon Research Publishing All rights reserved.

\begin{abstract}
The gear smoothness in the transmission of power mainly depends on the contact ratio. When the contact ratio is higher, the load shared by the pair of teeth in mesh will be lower. In the helical gear, the additional contact ratio is created due to face advance which is called face contact ratio and it provides the higher contact ratio than that of spur gear. The face contact ratio can improve by changing the few parameters such as helical lead and face width. In the present work, the face contact ratio is improved by altering those parameters and their effects on the load sharing based fillet stress are also determined for one mesh cycle in the asymmetric helical gear designed through direct design procedure using finite element method.
\end{abstract}

Keywords Asymmetric Helical Gear, Direct Design Method, Load Sharing Ratio, Fillet Stress, Face Contact Ratio

\section{Introduction}

The modern power transmission industries are needed an optimum design of high quality gears such as to have high load capacity, longer life, low weight and size. To achieve this requirement, it is necessary to reduce the tooth load which helps to lower the tooth stresses. The load sharing based maximum fillet stress analysis of helical gears with asymmetric teeth designed through direct design method is considered to be an effective method as it leads to the better one than the other methods. Helical gear with asymmetric involutes is a new kind gear which drive side surface is large pressure angle profile and coast side surface is low pressure angle profile. Direct gear design method is one of the most effective gear design approaches than the conventional method which provides the high performance gears without concern for any predefined tooling parameters. In this method, the pinion and gear are designed by using area of existence for a given pinion teeth number, speed ratio, coefficient of asymmetry and top land thickness coefficient. Di Francesco and Marini (1997) have investigated the structural analysis of asymmetric spur gear teeth in plain strain condition. Kahraman and G.W.Blankenship (1999) have investigated the influence of involute contact ratio on torsional vibration behavior of symmetric spur gear pair experimentally and proposed a simplified analytical model to describe the effect of involute contact ratio on dynamic transmission error. Alexander Kapelevich (2000) has developed the geometry and direct design procedure for the spur gear with asymmetric involute profiles to improve the load carrying capacity. Shyue-Cheng Yang (2005) has developed the mathematical model of a helical gear with asymmetric involute teeth and performed three dimensional stress analyses in the asymmetric helical gear. D.V. Muni et al. (2007) have studied the optimization of asymmetric spur gear drives for maximum bending strength using direct gear design method. Costopoulos and V.Spitas (2009) have proposed the asymmetric half - involute spur gear teeth geometry and also investigated the bending stresses at the root fillet. Rama Thirumurugan and Muthuveerappan (2010) had presented a method to calculate the maximum fillet stress based on load sharing ratio in NCR gears using SPLM of spur gear for different gear parameters. Contact ratio is defined as the maximum number of teeth in contact during the course of mesh along the line path of contact. If more number of teeth comes in contact, the maximum load shared by the pair of teeth in mesh will reduce which enables gear to transmit high power. In the helical gear, the additional contact ratio is created due to face advance which is called face contact ratio and it provides the higher contact ratio than that of spur gear. The face contact ratio can improve by changing the few parameters such as helical lead and face width. Several attempts have been made so far on stress analysis of symmetric and asymmetric spur gears but only a few are available on fillet stress analysis of asymmetric helical gears. However, comparative study using FEM on LSR based maximum fillet stress $\left(\sigma_{t}\right)_{\max }$ has not been dealt with. Hence, in the present work, the load sharing ratio and the respective maximum fillet stress are determined for one mesh cycle in the asymmetric helical gears designed through direct designed method. It is also aimed to explore the influence of face width and helical lead on the LSR based 
stress analysis of asymmetric helical gear.

\section{Direct Gear Design Method}

In the conventional gear design method, the generating rack is standardized first by preselecting the gear parameters such as module, pressure angle, addendum and dedendum proportions, tip radii and addendum shift etc. In this method, the minimum number of teeth is limited to avoid undercut and it can reduce to give the addendum modification (x-shift) to the pinions with small numbers of teeth. The range of gear combinations is also limited. Direct gear design gives the all possible gear combinations by analyzing their properties without using any of the generating rack parameters. In this method, the pinion and gear are designed by using an area of existence procedure with the given pinion teeth number, gear ratio, coefficient of asymmetry and top land thickness coefficient. This method optimizes the tooth profiles and significantly reduces the fillet stresses. This improves load capacity, reduces size and weight and extends life.

\subsection{Geometry of Asymmetric Profile}

The asymmetric profile at the coast side and drive sides of the gear tooth in the transverse section generated based on the respective base circle diameter $d_{b c t}$ and $d_{b d t}$ are shown in Fig.1. The top land thickness coefficient $\mathrm{L}_{\mathrm{at}}$ and coefficient of asymmetry $\mathrm{k}$ are defined as

$$
\begin{gathered}
\mathrm{L}_{\mathrm{at}}=\frac{\mathrm{T}_{\mathrm{at}}}{2 \mathrm{r}_{\mathrm{bdt}}}=\frac{\left(\mathrm{inv} v_{\mathrm{dt}}+\mathrm{inv} v_{\mathrm{ct}}-\mathrm{inv} \alpha_{\mathrm{adt}}-\mathrm{inv} \alpha_{\mathrm{act}}\right)}{2 \cos \alpha_{\mathrm{adt}}} \\
\mathrm{k}=\frac{\cos v_{\mathrm{ct}}}{\cos v_{\mathrm{dt}}}=\frac{\cos \alpha_{\text {oct }}}{\cos \alpha_{\text {odt }}}=\frac{\mathrm{r}_{\mathrm{bct}}}{\mathrm{r}_{\mathrm{bdt}}}
\end{gathered}
$$

In a gear drive of a gear ratio $i$, the relation between the pressure angles of the drive side and that of coast side at the pitch circle is given as

$$
\operatorname{inv} \alpha_{\text {odt }}+\operatorname{inv} \alpha_{\text {oct }}=\frac{\left(\text { inv } v_{\text {pdt }}+\text { inv } v_{\text {pct }}\right)+i\left(\text { inv } v_{g d t}+\text { inv } v_{g c t}\right)-\frac{2 \pi}{z_{p}}}{1+\mathrm{i}}
$$

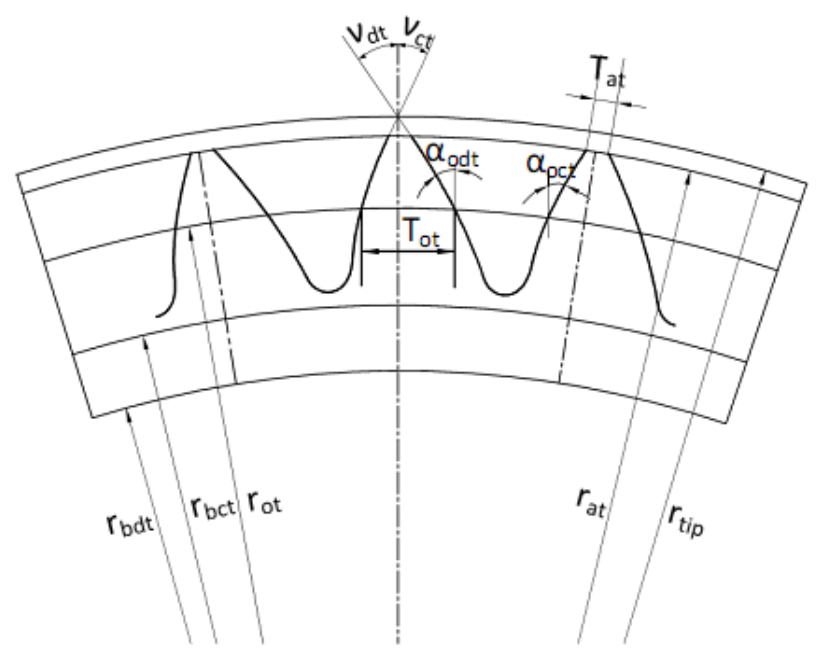

Figure 1. Asymmetric tooth profile
The transverse contact ratio at the drive side $\varepsilon_{\mathrm{sd}}$ is given as

$$
\varepsilon_{\text {sd }}=\frac{z_{\mathrm{p}}\left(\tan \alpha_{\text {apdt }}+\mathrm{i} \tan \alpha_{\text {agdt }}-(1+\mathrm{i}) \tan \alpha_{\text {odt }}\right)}{2 \pi}
$$

The relation between the lead of the helical gear $\left(\mathrm{L}_{\mathrm{h}}\right)$ and the helix angle at pitch surface is given as

$$
\tan \beta=\frac{\pi d_{\text {odt }}}{L_{h}}
$$

The face contact ratio at the drive side of the helical gear is given as

$$
\varepsilon_{\mathrm{fd}}=\frac{\left(\mathrm{bzz}_{\mathrm{p}}\right)}{\mathrm{L}_{\mathrm{h}}}
$$

\subsection{Area of Existence of Asymmetric Gears}

An area of existence is the region enclosed between the isograms $A_{i}, B_{i}$ and $C_{i}$, which is used to select the different possible design solution for the pinion and gear if the input parameters such as $\mathrm{z}_{\mathrm{p}}, \mathrm{z}_{\mathrm{g}}, \mathrm{i}, \mathrm{k}$ and $\mathrm{L}_{\mathrm{at}}$ are given (Fig 2). The minimum requirements of gear mesh conditions to accomplish the isograms $A_{i}, B_{i}$ and $C_{i}$ are as

1) The isograms $A_{i}$ are drawn based on the minimum transverse contact ratio at drive side should be always greater than or equal to $1\left(\varepsilon_{\mathrm{sd}} \geq 1\right)$.

2) The isograms $B_{i}$ are drawn based on the fact that avoids the interference and undercutting. For that, the transverse pressure angle at limiting circle of the pinion and the gear should be greater than or equal to zero $\left(\alpha_{\text {lpct }} \geq 0\right.$ and $\left.\alpha_{\text {lgct }} \geq 0\right)$.

3) The isograms $C_{i}$ are drawn for minimum addendum such that respective angle at the pitch point of the pinion or the gear should satisfy the condition that $\alpha_{\text {apdt }} \geq \alpha_{\text {odt }}$ and $\alpha_{\text {agdt }} \geq \alpha_{\text {odt }}$ to have a definite contact at the pitch point.

From the area of existence, the possible existence of design solutions for the drive of some given input parameters at different addendum pressure angles $\left(\alpha_{\text {apdt }}\right.$ and $\left.\alpha_{\text {agdt }}\right)$ of the pinion and the gear are chosen to develop the rack dimensions for a required constant transverse contact ratio.

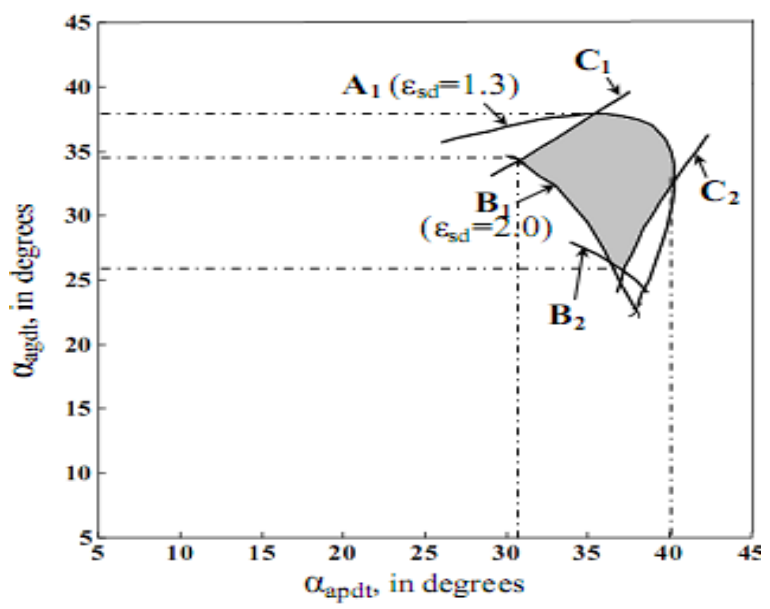

Figure 2. The area of existence for the pinion and the gear for different $\varepsilon_{\text {sd }}$ and $\alpha_{\text {odt }}\left(\mathrm{k}=1.1, \mathrm{i}=3, \mathrm{z}_{\mathrm{p}}=40\right)$ 


\subsection{Contact Ratio and Load Sharing Ratio}

Total Contact ratio $\left(\varepsilon_{\mathrm{Td}}\right)$ is defined as a measure of the average number of teeth in contact during a mesh cycle. To ensure smooth and continuous operation, the contact ratio at drive side $\left(\varepsilon_{\mathrm{Td}}\right)$ must be made as high as possible, say a value of $\varepsilon_{\mathrm{Td}}>2$ for a helical gear drive and it is defined as

$$
\varepsilon_{\mathrm{Td}}=\frac{\mathrm{z}_{\mathrm{p}}\left(\tan \alpha_{\mathrm{apdt}}+\mathrm{i} \tan \alpha_{\mathrm{agdt}}-(1+\mathrm{i}) \tan \alpha_{\mathrm{odt}}\right)}{2 \pi}+\left(\frac{\mathrm{b} * \mathrm{z}_{\mathrm{p}}}{\mathrm{L}_{\mathrm{h}}}\right)
$$

The Load Sharing Ratio is defined as the ratio of the load shared by one of the pairs to the total normal load $\left(F_{n}\right)$. The tooth load is assumed to be acting always in a direction normal to the tooth surface. The normal tooth load $\left(F_{n}\right)$ on the tooth surface, can be resolved into three as tangential component $F_{t}$, radial component $F_{r}$ and axial component $F_{a}$ (Fig.3). Considering the number of loading nodes as $\mathrm{N}_{\mathrm{i}}$ in a contact line, the corresponding deflection $\left(\delta_{\mathrm{i}}\right)$ at each node for an individual normal load of $F_{n}$ is determined and the stiffness $\mathrm{k}_{\mathrm{i}}$ of the tooth with respect to a load at this nodal point is defined as $\left(\mathrm{F}_{\mathrm{n}} / \delta_{\mathrm{i}}\right)$ from which the load shared at each nodal point is evaluated from (8).

$$
\mathrm{F}_{\mathrm{i}}=\frac{\mathrm{k}_{\mathrm{i}}}{\sum \mathrm{k}_{\mathrm{i}}} * \mathrm{~F}_{\mathrm{n}}
$$

Then, this $F_{i}$ further distributed through the $\mathrm{N}_{\mathrm{i}}$ nodes of the $\mathrm{N}_{\mathrm{j}}$ contact lines of the pinion and the gear, the corresponding deflections $\delta_{\mathrm{pj}}, \delta_{\mathrm{gj}}$ at each contact line for an individual normal load of $F_{n}\left(\sum F_{i}=F_{n}\right)$ is calculated and the stiffness of the $\mathrm{k}_{\mathrm{pj}}, \mathrm{k}_{\mathrm{gj}}$ (Fig.4) at different contact positions are determined (Eqs 12-14). The load shared by the individual tooth pair is evaluated based on stiffness of the tooth pair from Eqs. 9-11

$$
(\mathrm{LSR})_{\text {pair } 1}=\frac{\mathrm{k}_{\text {equ } 1}}{\left(\mathrm{k}_{\text {equ } 1}+\mathrm{k}_{\text {equ } 2}+\mathrm{k}_{\text {equ } 3}\right)}
$$

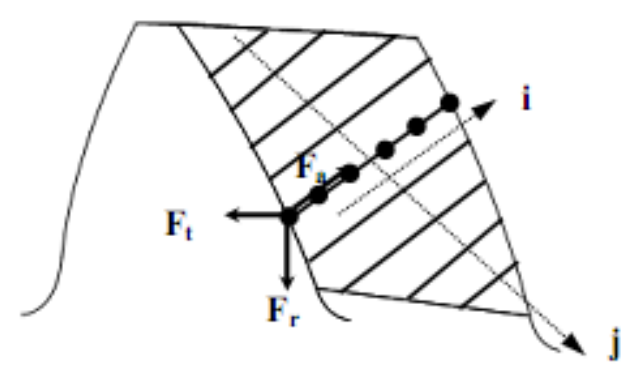

Figure 3. Forces acting on the nodes

\section{Finite Element Model}

The 3D finite element model of asymmetric helical gear displayed in Fig. 5 is for the three teeth sector model, which is used to carry out the analysis. A higher order 3-D SOLID 186, 20 node hexahedron element is used for the analysis. The material is linear elastic isotropic and homogeneous with elastic constant of $E=210 \mathrm{GPa}$ and Poisson's ratio of $\gamma=0.3$. Boundary conditions that left and right edges are allowed to move in the radial direction and the inner gear hub is constrained in all the directions.

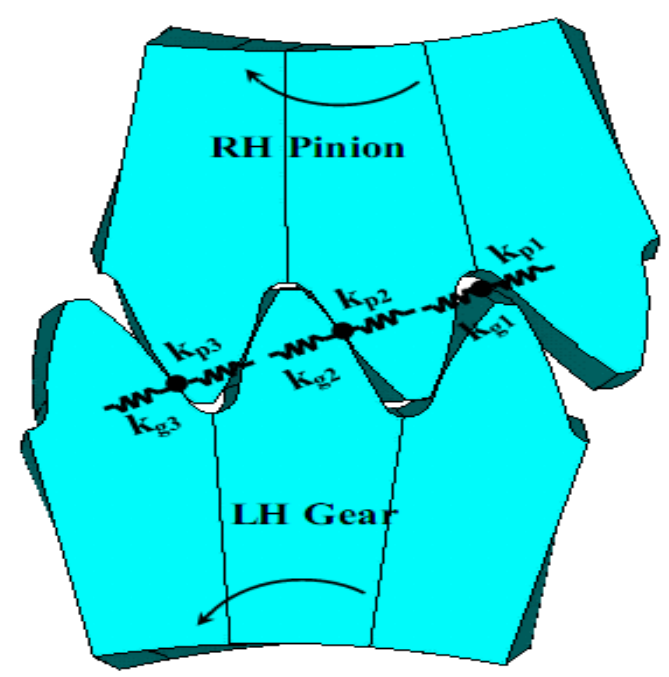

Figure 4. Spring model of asymmetric pinion and gear teeth contact pairs

$$
\begin{aligned}
& (\mathrm{LSR})_{\text {pair 2 }}=\frac{\mathrm{k}_{\text {equ 2 }}}{\left(\mathrm{k}_{\text {equ } 2}+\mathrm{k}_{\text {equ } 2}+\mathrm{k}_{\text {equ 3 }}\right)} \\
& (\mathrm{LSR})_{\text {pair 3 }}=\frac{\mathrm{k}_{\text {equ } 3}}{\left(\mathrm{k}_{\text {equ } 2}+\mathrm{k}_{\text {equ } 2}+\mathrm{k}_{\text {equ 3 }}\right)}
\end{aligned}
$$

The equivalent stiffness of the tooth pair is calculated from the individual tooth stiffness of the pinion and the gear given as

$$
\begin{aligned}
& \mathrm{k}_{\mathrm{equ} 1}=\frac{\left(\mathrm{k}_{\mathrm{pj} 1} * \mathrm{k}_{\mathrm{gj} 1}\right)}{\left(\mathrm{k}_{\mathrm{pj} 1}+\mathrm{k}_{\mathrm{gj} 1}\right)} \\
& \mathrm{k}_{\mathrm{equ} 2}=\frac{\left(\mathrm{k}_{\mathrm{pj} 2} * \mathrm{k}_{\mathrm{gj} 2}\right)}{\left(\mathrm{k}_{\mathrm{pj} 2}+\mathrm{k}_{\mathrm{gj} 2}\right)} \\
& \mathrm{k}_{\mathrm{equ} 3}=\frac{\left(\mathrm{k}_{\mathrm{pj} 3} * \mathrm{k}_{\mathrm{gj} 3}\right)}{\left(\mathrm{k}_{\mathrm{pj} 3}+\mathrm{k}_{\mathrm{gj} 3}\right)}
\end{aligned}
$$

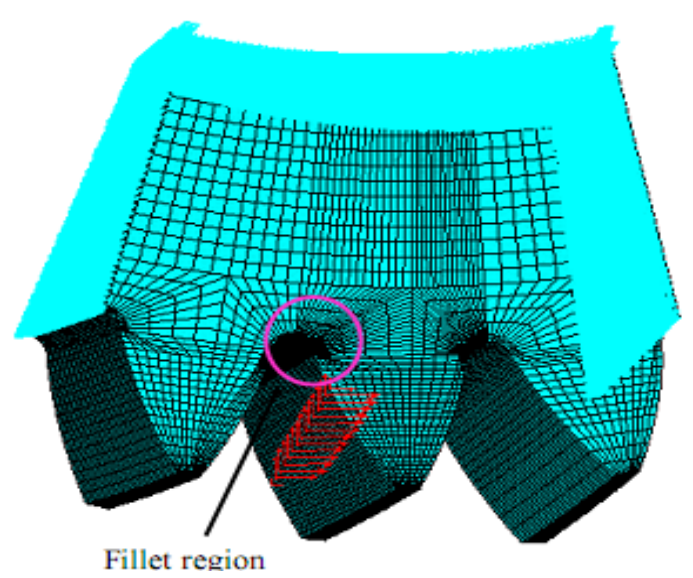

Figure 5. 3D Finite Element Model

\section{Results and Discussions}

As an accurate estimation of maximum fillet stress in gears becomes an important concern to improve their load carrying capacity and to reduce the tooth failure at the fillet 
region. A few parameters like helical lead and face width (as detailed in table 1) are considered to study their influence on LSR and $\left(\sigma_{t}\right)_{\max }$ using the finite element model in this analysis. The Fig. 6 shows the fillet region and the maximum stress distribution at that region (nodal points).

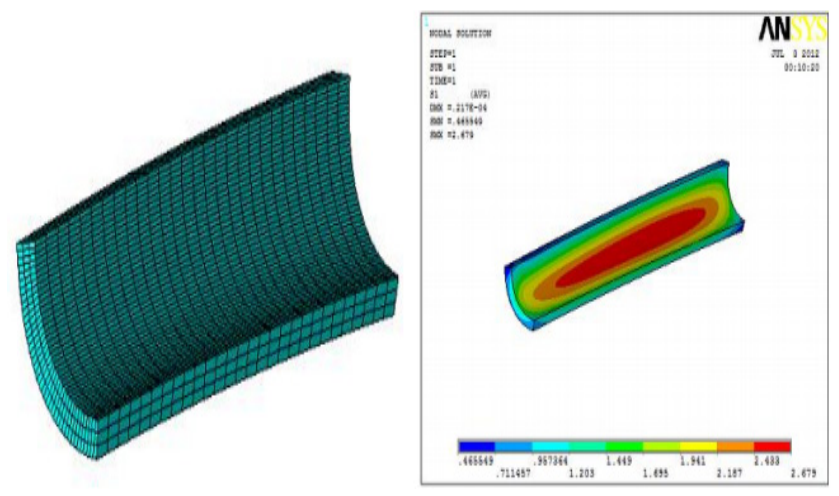

Figure 6. Maximum fillet stress at fillet region

\subsection{Influence of Face Width}

The calculated LSR and the corresponding $\left(\sigma_{t}\right)_{\max }$ are determined in the direct designed asymmetrical helical gear of the right hand pinion are shown in Figs. 8 ((a) and (b)).The values are plotted against the non-dimensional parameter $\left(\mathrm{x} / \mathrm{p}_{\mathrm{bt}}\right) . \mathrm{x}$ is the different contact positions along the line of contact. In the Figs. 7 and 8a, AB, CD and EF indicate the triple pairs contact regions while $\mathrm{BC}$ and $\mathrm{DE}$ are the double pairs contact regions. $\mathrm{L}$ is the critical loading position. An increase in face width does not alter the LSR either at A (LPTC) or at F (HPTC) but there are significant increase in the values of LSR at the contact lines through $\mathrm{E}$ and $\mathrm{B}$, as a consequence, there is a significant decrease in it due to load contact in the triple pair contact region C-D as shown in (Fig (8a)). Because of the shifting of E away from F (HPTC), the moment arm is reduced and hence, the $\left(\sigma_{t}\right)_{\max }$ is significantly reduced (from 2.633 to $1.711 \mathrm{MPa}$ ) (Fig (8b)), even though there is a significant increase in the LSR values. It is generally observed for a contact ratio greater than two, the maximum fillet stress $\left(\sigma_{t}\right)_{\max }$ decreases with increase in face width and it is higher always due to load at critical contact line through $\mathrm{E}(\mathrm{L})$ in the double pair contact region, which is an expected trend.

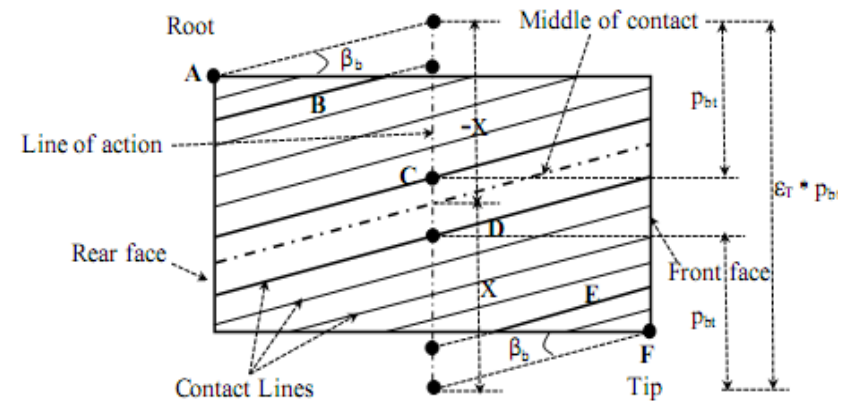

Figure 7. Different contact positions along the line of contact
Table 1. Gear Parameters

\begin{tabular}{|l|c|}
\hline \multicolumn{1}{|c|}{ Parameters Name } & Data \\
\hline Pinion teeth number $\left(\mathrm{z}_{\mathrm{l}}\right)$ & 40 \\
Gear ratio $(\mathrm{i})$ & 3 \\
Coefficient of symmetry $(\mathrm{k})$ & 1.1 \\
Helical lead $\left(\mathrm{L}_{\mathrm{h}}\right)(\mathrm{mm})$ & $1030,520,350$ \\
Face width $(\mathrm{b})(\mathrm{mm})$ & $6,7.2,8.4$ \\
Transverse contact ratio $\left(\varepsilon_{\mathrm{sd}}\right)$ & 1.70 (constant) \\
& \\
Face contact ratio $\left(\varepsilon_{\mathrm{fd}}\right)$ & \\
1. For different $\mathrm{L}_{\mathrm{h}}(1030,520,350)(\mathrm{mm})$ & $0.326,0.647,0.958$ \\
& \\
2. For different $\mathrm{b}(6,7.2,8.4)(\mathrm{mm})$ & $0.462,0.554,0.647$ \\
\hline
\end{tabular}

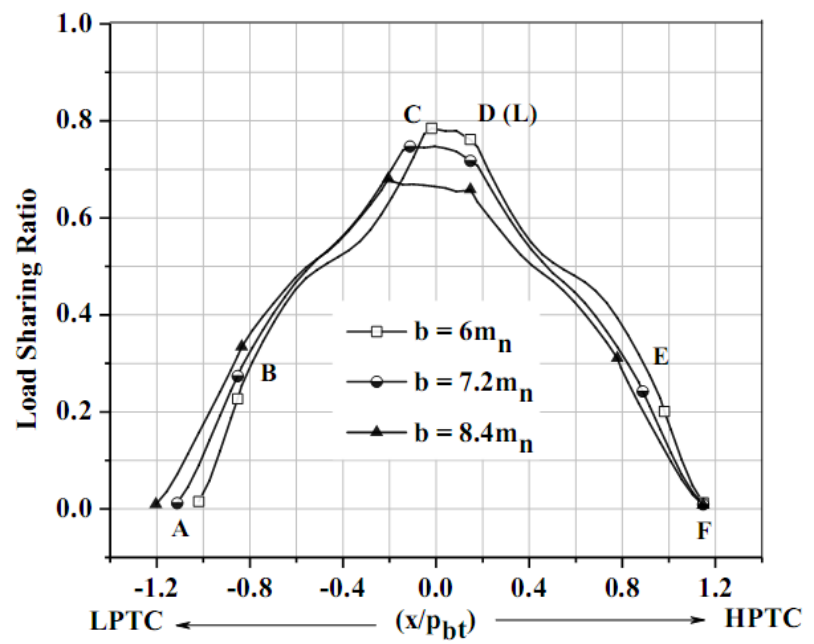

(a) LSR Vs Contact position

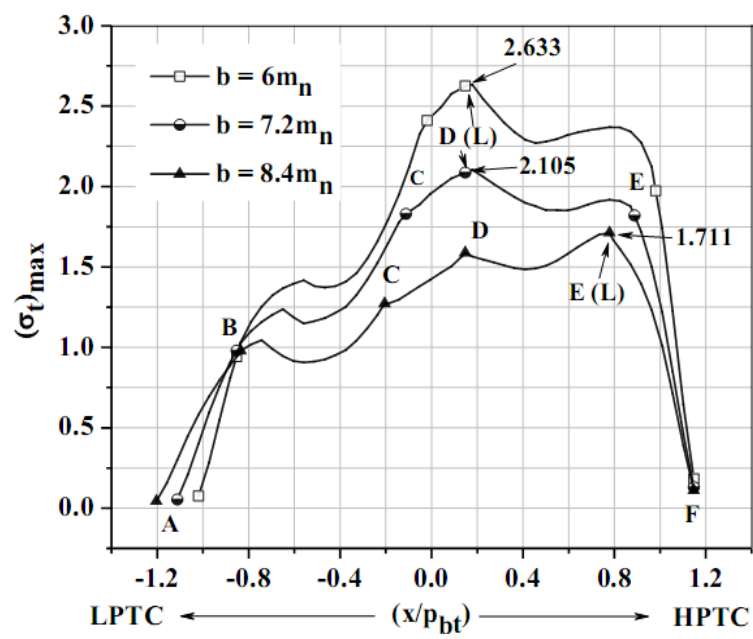

(b) $\left(\sigma_{t}\right)_{\max }$ Vs Contact position

Figure 8. Influence of Face width

\subsection{Influence of Helical Lead}


The helix angle and the total contact ratio of helical gear increases with decrease the helical lead (Eqs. 5 - 17and table. 1 ) in the asymmetric helical gear. Due to an increase in helix angle, the contact ratio also increases beyond two and hence the emergence of triple tooth contact region begins and apparently the gap between the point A (LPTC) and the middle line as well as the gap between the point F (HPTC) and the middle line widen. Because of this, there is a decrease in the values of LSR and the respective $\left(\sigma_{t}\right)_{\max }$ (from 2.309 to $1.659 \mathrm{MPa}$ ) (Figs.(9(a),(b)). Ultimately it is observed that the highest $\left(\sigma_{t}\right)_{\max }$ is developed due to load or contact at the critical line through E (L) in the double tooth contact region. It is also noted that it is true only for contact ratio greater than two at the higher helix angle.

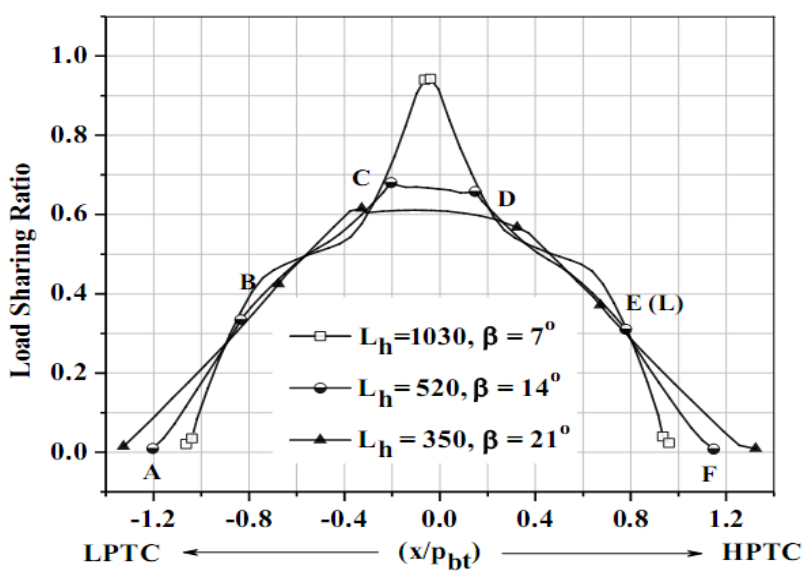

(a) LSR Vs Contact position

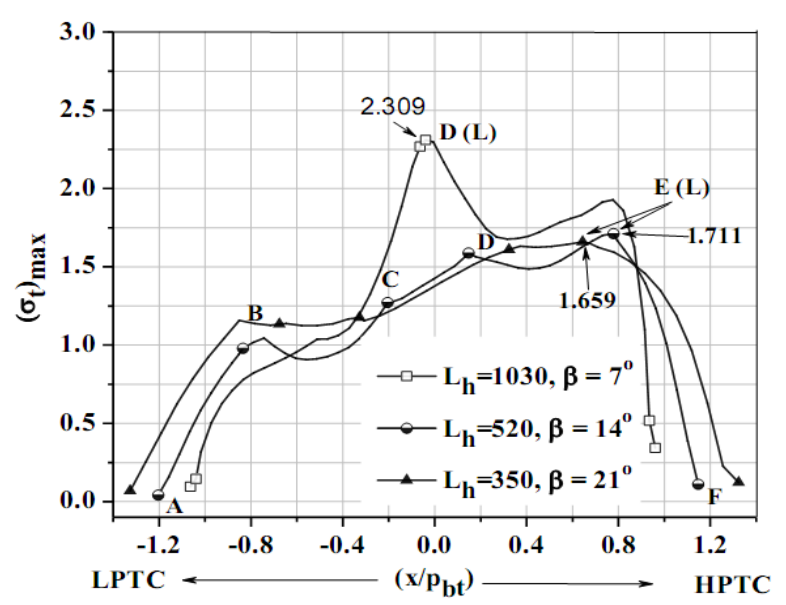

(b) $\left(\sigma_{t}\right)_{\max }$ Vs Contact position

Figure 9. Influence of Helical lead

\section{Conclusions}

This work presents the effects of face width and helical lead on LSR and the respective $\left(\sigma_{t}\right)_{\max }$ of helical gears. The major conclusions of this study are

1. The face contact ratio is higher with higher face width and lower the helical lead in the asymmetric helical gear.

2. As the face width increases from (6 to $8.4 \mathrm{~mm}$ ), the contact ratio increases, which leads to the widen in three pair contact regions $\mathrm{CD}$, in consequence there is an decrease in LSR and $\left(\sigma_{t}\right)_{\max }$. When the critical loading line E (L) is considered, the values of LSR increases, but the corresponding $\left(\sigma_{t}\right)_{\max }$ decreases due to decrease the moment arm, which is an expected trend (Figs. $8 \mathrm{a}$ and $\mathrm{b}$ ).

3. Due to decrease the helical lead, the helix angle and the contact ratio increases, in turn the values of LSR increases accordingly at the critical load line E (L), which tends to decrease $\left(\sigma_{t}\right)_{\max }$ in a mesh cycle (Figs. $9 \mathrm{a}$ and $\mathrm{b})$.

\section{REFERENCES}

[1] Alexander Kapelevich (2000), Geometry and design of involute spur gears with asymmetric teeth, Mechanism and Machine Theory, 35, 117-130.

[2] Costopoulos.Th and V.Spitas (2009), Reduction of gear fillet stresses using one side asymmetric teeth, Mechanism and Machine Theory, 44, 1524-1534.

[3] Di Franceco and S. Marini, (1997), Structural analysis of asymmetrical teeth: reduction of size and weight, Gear technology, 14, 47-51.

[4] Kahraman.A and G.W. Blankenship (1999), Effect of Involute Contact Ratio on Spur Gear Dynamics, Mechanical Design-ASME, 121, 112-118.

[5] Shyue-Cheng Yang (2005), Mathematical model of a helical gear with asymmetric involute teeth and its analysis, International J Adv Manuf Technol, 26, 448-456.

[6] D.V. Muni, Senthil Kumar.V, and G.Muthuveerappan (2007) Optimization of asymmetric spur gear drives for maximum bending strength using direct gear design method, Mechanics based design of structures and Machines: An International journal, 35, 127-145.

[7] Rama Thirumurugan and G. Muthuveerappan (2010) Maximum fillet stress analysis based on load sharing in normal contact ratio spur gear drives, Mechanics based design of structures and Machines: An International journal, 38, 204-226. 